\title{
Adaptive thermogenesis and uncoupling proteins: a reappraisal of their roles in fat metabolism and energy balance
}

\author{
Abdul G. Dulloo ${ }^{\mathrm{a}, *}$, Josiane Seydoux ${ }^{\mathrm{a}}$, Jean Jacquet ${ }^{\mathrm{b}}$ \\ ${ }^{a}$ Department of Medicine, Division of Physiology, University of Fribourg, Rue du Musée 5, CH-1700 Fribourg, Switzerland \\ ${ }^{\mathrm{b}}$ Computer Unit, Faculty of Medicine, University of Geneva, Switzerland
}

Received 27 July 2004; accepted 27 July 2004

\begin{abstract}
After decades of controversies about the quantitative importance of autoregulatory adjustments in energy expenditure in weight regulation, there is now increasing recognition that even subtle variations in thermogenesis could, in dynamic systems and over the long term, be important in determining weight maintenance in some and obesity in others. The main challenge nowadays is to provide a mechanistic explanation for the role of adaptive thermogenesis in attenuating and correcting deviations of body weight and body composition, and in the identification of molecular mechanisms that constitute its effector systems. This workshop paper reconsiders what constitutes adaptive changes in thermogenesis and reassesses the role of the sympathetic nervous system (SNS) and uncoupling proteins (UCP1, UCP2, UCP3, $\mathrm{UCP} 5 / \mathrm{BMCP} 1)$ as the efferent and effector components of the classical one-control system for adaptive thermogenesis and fat oxidation. It then reviews the evidence suggesting that there are in fact two distinct control systems for adaptive thermogenesis, the biological significance of which is to satisfy - in a lifestyle of famine-and-feast - the needs to suppress thermogenesis for energy conservation during weight loss and weight recovery even under environmental stresses (e.g., cold, infection, nutrient imbalance) when sympathetic activation of thermogenesis has equally important survival value.
\end{abstract}

Keywords: Obesity; Diabetes; Cachexia; Catecholamines; UCP

\section{Resistance to obesity in an obesigenic environment}

One of the greatest challenges towards understanding the aetiology of human obesity is to explain how in environments that promote overeating of high-fat foods and discourage physical activity, there is always a section of the population who, apparently without conscious effort, do not become obese. How do they resist obesity? How is constancy of body weight achieved over decades in these individuals? In addressing the issue of human susceptibility to leanness and fatness, there are three cardinal features of body weight regulation that need to be underlined:

(i) Humans cannot escape the laws of thermodynamics. Whatever theory is put forward to explain body weight

\footnotetext{
* Corresponding author. Tel.: +41 26300 8624; fax: +41 263009734 .

E-mail address: abdul.dulloo@unifr.ch (A.G. Dulloo).
}

and body composition regulation, it is undeniable that changes in body energy stores (and ultimately body weight) cannot occur unless there is a difference between energy intake and energy expenditure.

(ii) Subtle perturbations in energy balance can lead to obesity. To put it another way, long-term constancy of body weight can only be achieved if the matching between energy intake and energy expenditure is extremely precise, since an error of only $1 \%$ between input and output of energy, if persistent, will lead to a gain or loss of $1 \mathrm{~kg}$ per year or some $40 \mathrm{~kg}$ between the age of 20 to 60 years. Yet, a difference of $5 \%$ between energy intake and energy expenditure is hardly measurable with available techniques.

(iii) Body weight is a fluctuating and oscillatory phenomenon. Even in individuals that maintain a relatively stable lean body weight over decades, there is no 'absolute' constancy of body weight over days, 
weeks, and years. Instead, body weight tends to fluctuate or oscillate around a mean constant value, with deviations from a 'set' or 'preferred' value being triggered by events that are cultural (weekend parties, holiday seasons), psychological (stress, anxiety or emotions), and pathophysiological (ranging from minor health perturbations to more serious disease states). According to Garrow [1], very short-term dayto-day changes in body weight have a standard deviation of about $0.5 \%$ of body weight, while longitudinal observations over periods of between 10 and 30 years indicate that individuals experienced slow trends and reversal of body weight amounting to between $7 \%$ and $20 \%$ of mean weight.

In such a dynamic state within which weight homeostasis occurs, it is likely that long-term constancy of body weight is achieved through a network of regulatory systems and subsystems through which autoregulatory changes in food intake, body composition, and energy expenditure are interlinked.

\section{Weight regulation through adjustments in energy expenditure}

There is in fact a built-in stabilising mechanism in the overall homeostatic system for body weight. As Payne and Dugdale [2] have illustrated, using a mathematical model for weight regulation, any imbalance between energy intake and energy requirements would result in a change in body weight which in turn will alter the maintenance energy requirements in a direction which will tend to counter the original imbalance and would hence be stabilising. The system thus exhibits dynamic equilibrium. For example, an increase in body weight will be predicted to increase metabolic rate (on the basis of the extra energy cost for synthesis and subsequent maintenance of extra lean and fat tissues), which will produce a negative energy balance and hence a subsequent decline in body weight. Similarly, a reduction in body weight would also be automatically corrected inasmuch as the resulting diminished metabolic rate due to the loss in weight will produce a positive balance and hence a subsequent return towards the 'set' or 'preferred' weight. But in reality, the homeostatic system is much more complex than this simple effect of mass action. As demonstrated in the 'weight-clamping' experiments of Leibel et al. [3], subjects forced to maintain body weight at a level $10 \%$ above their initial body weight showed an increase in daily energy expenditure even after adjusting for changes in body weight and body composition. Conversely, in subjects maintaining weight at a level $10 \%$ below the initial body weight, daily energy expenditure was also lower after adjusting for losses in weight and lean tissues. These compensatory changes in energy expenditure ( $\sim 15 \%$ above or below predicted values) reflect changes in metabolic efficiency (ME) that oppose the maintenance of a body weight that is above or below the 'set' or 'preferred' body weight.

A closer inspection of the data from this 'weightclamping' experiment [3] reveals a large interindividual variability in the ability to readjust energy expenditure, with some individuals showing little or no evidence for altered metabolic efficiency, while others reveal a marked capacity to decrease or increase energy expenditure through alterations in metabolic efficiency. Indeed, the most striking feature of virtually all experiments of human overfeeding usually on diets in which fat contributed more than $35 \%$ of energy - is the wide range of individual variability in the amount of weight gain per unit of excess energy consumed. Some of these differences in the efficiency of weight gain could be attributed to interindividual variability in the gain of lean tissue relative to fat tissue (i.e., variability in the composition of weight gain), but most is in the ability to convert excess calories to heat, i.e., in the large interindividual capacity for diet-induced thermogenesis (DIT). In his detailed reanalysis of data from some 150 human beings participating in the various 'Gluttony Experiments' conducted between 1965 and 1999, Stock [4] argues that at least $40 \%$ of these overfed subjects (on high-fat diets) must have exhibited an increase in DIT, albeit to varying degrees. Part of this variation in DIT could be explained by differences in the dietary protein content of the diet, with DIT being more pronounced on unbalanced diets which are low or high in $\%$ protein [4]. Indeed, our own reanalysis of the classic human overfeeding studies of the 1960 s revealed that relatively small individual differences in DIT on balanced normalprotein diet are amplified on protein-deficient diets [5]. That genes play an important role in variability in metabolism that underlie susceptibility to weight gain and obesity has in fact been established from overfeeding experiments of Bouchard et al. in identical twins [6]. Conversely, a role for genotype in human variability in enhanced metabolic efficiency during weight loss has been suggested from studies of Hainer et al. [7], in which identical twins underwent slimming therapy on a very low-calorie diet.

Taken together, it is evident that, in addition to the control of food intake, changes in efficiency of energy utilization (i.e., in adaptive thermogenesis) also play an important role in the regulation of body weight and body composition, and that the magnitude of adaptive changes in thermogenesis is strongly influenced by the genetic makeup of the individual.

\section{What constitutes adaptive thermogenesis?}

A main reason for controversies about the importance of adaptive thermogenesis in the aetiology of human obesity reside in difficulties in pinpointing which component(s) of energy expenditure could be contributing importantly to the changes in metabolic efficiency and hence in adaptive 
thermogenesis. As depicted in Fig. 1, the energy expenditure measured in the resting state, whether as basal metabolic rate (BMR) or as thermic effect of food (TEF), certainly results in the production of heat (i.e., in thermogenesis), and changes in resting energy expenditure that are unaccounted for changes in body weight and body composition reflect changes in metabolic efficiency and hence in adaptive changes in thermogenesis. By contrast, the heat production from what is generally clustered under nonresting energy expenditure is more difficult to quantify. The efficiency of muscular contraction during exercise is low $(\sim 25 \%)$, but that of spontaneous physical activity (SPA) (including fidgeting, muscle tone and posture maintenance, and other low-level physical activities of everyday life) is even lower since these essentially involuntary activities comprise a larger proportion of isometric work which is simply thermogenic. Because actual work done on the environment during SPA is very small compared to the total energy spent on such activities, the energy cost associated with SPA has been referred to as movement-associated thermogenesis or SPA-associated thermogenesis [8]. It can also be argued that since SPA is essentially beyond voluntary control, a change in the level or amount of such involuntary SPA in a direction that defends body weight also constitute autoregulatory changes in energy expenditure. In this context, an increase in the amount of SPA in response to overfeeding or a decrease during starvation also constitutes adaptive changes in thermogenesis.

To date, the most direct evidence that changes in SPA contribute to autoregulatory changes in energy expenditure in humans derived from data obtained from the eight men and women who were participating in the Biopshere 2 experiment, a self-contained ecologic 'miniworld' and prototype planetary habitat built in Arizona. As a result of unexpected shortage of food, their losses in body weight (8$25 \%$ ) over a 2 -year period was found to be accompanied by a major reduction in SPA, which, like their reduced energy expenditure, persisted several months after the onset of weight recovery and disproportionate recovery of fat mass [9]. Whether interindividual variability in the amount of SPA during overfeeding contributes to variability in resistance or susceptibility to obesity has also been the focus of a few human studies of energy expenditure. The importance of SPA-associated thermogenesis in human weight regulation was in fact underscored by the findings of Ravussin et al. [10], that even under conditions where subjects are confined to a metabolic chamber, the 24-h energy expenditure attributed to SPA (as assessed by radar systems) was found to vary between $100,700 \mathrm{kcal} /$ day and to be a predictor of subsequent weight gain. In fact, a main conclusion of the early overfeeding experiments of Miller et al. [11] was that most of extra heat dissipation in some of the individuals resisting obesity by increased DIT could not be accounted for an increase in resting metabolic rate but could be due to an increased energy expenditure associated with simple (low-level) activities of everyday life. This notion has recently gained much support from the findings of Levine et al. [12] that more than $60 \%$ of the increase in total daily energy expenditure in response to overfeeding could be attributed to SPA, and that interindividual variability in energy expenditure associated with SPA - which they referred to as nonexercise-activity thermogenesis (NEAT) - was the most significant predictor of the resistance or susceptibility to obesity.

Although SPA is likely to play an important role in weight regulation, there is however no consistent evidence to suggest that SPA is the major component in adaptive thermogenesis. Indeed, in the 'weight-clamping' experiments whereby subjects maintained body weight at $10 \%$ above or $10 \%$ below their habitual body weight [3], the autoregulatory increases or decreases in nonresting energy expenditure could not be explained by the amount of time spent in physical activity. Instead, changes in muscle work

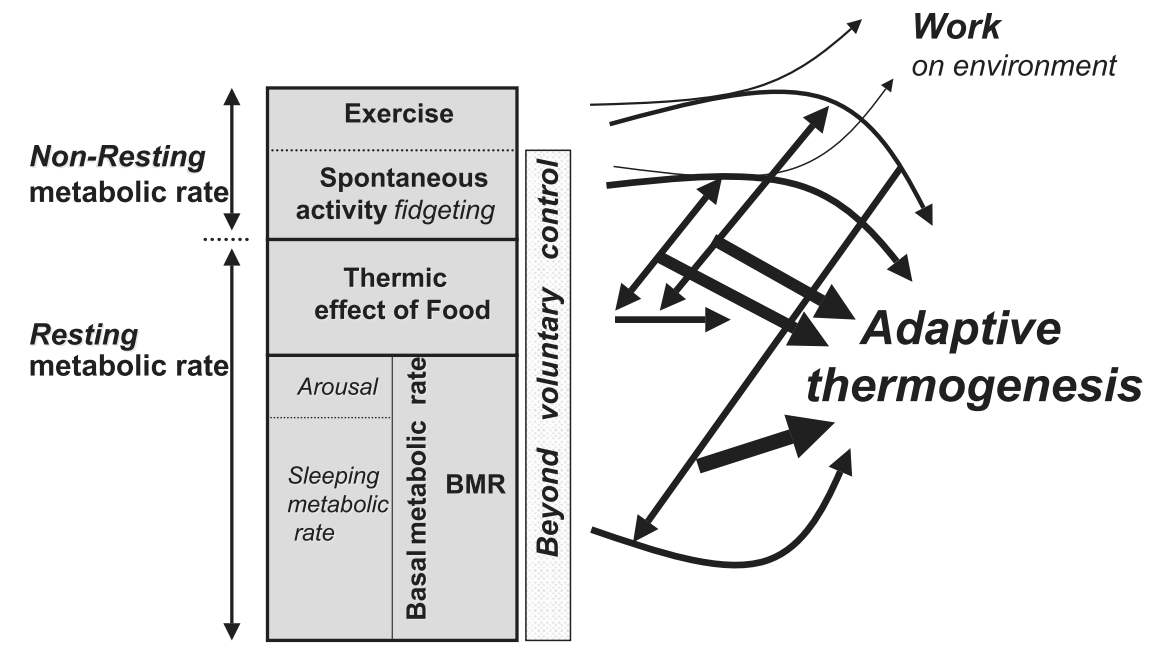

Fig. 1. Schematic diagram showing the various compartments of human energy expenditure, and how changes in metabolic efficiency ( $\Delta$ ME) both within and across these compartments can lead to adaptive changes in thermogenesis. See text for details. 
Table 1

Reports of 'variations in thermogenesis' in humans occurring through changes

\begin{tabular}{ll}
\hline In nonresting EE & In resting EE \\
\hline - Rapid 'Gluttony' experiments & - Low BMR: a risk factor for \\
(Miller et al. [11]; Levine & obesity (Griffiths et al. [112]; \\
et al. [12]) & Ravussin et al. [113]) \\
- 'Weight-clamping' experiments & - The 'Minnesota Experiment' \\
at +10\% or $-10 \%$ of initial & of starvation/refeeding/ \\
weight (Leibel et al. [3]) & overfeeding (Keys et al. [107]; \\
& Dulloo and Jacquet [108]) \\
- The Biosphere study (after 2 years & - The Biosphere study (after 2 \\
of prolonged moderate starvation; & years of prolonged moderate \\
Weyer et al. [9]) & starvation; Weyer et al. [9]) \\
\hline
\end{tabular}

efficiency could account for a third of the change in daily energy expended in physical activity [13], findings which are consistent with previous reports of an increase in skeletal muscle work efficiency (i.e., decreased thermogenesis) after experimentally induced weight reduction $[14,15]$ or in chronically undernourished subjects [16].

Some of the most compelling evidence that changes in adaptive thermogenesis can occur in both resting and nonresting components of energy expenditure are listed in Table 1. It must be emphasized that the separation of adaptive thermogenesis between resting and nonresting is artificial, given the possibilities of their interactions illustrated in Fig. 1. For example, energy expenditure during sleep, which is generally nested under 'resting' energy expenditure, also comprises a 'nonresting' component due to spontaneous movement (or SPA) occurring during sleep, the frequency of which seems to be highly variable between individuals. Furthermore, nonresting energy expenditure or NEAT could also include heat production resulting from the impact of physical activity (exercise or SPA) on postabsorptive metabolic rate or postprandial thermogenesis. There is in fact some evidence that relatively low-intensity exercise can lead to potentiation of TEF $[11,17]$ and that the effect of physical activity on energy expenditure can persist well after the period of the physical activity (postexercise or post-SPA stimulation of thermogenesis) [17]. Nonetheless, any changes in metabolic efficiency (ME) in resting or nonresting state that would tend to attenuate energy imbalance or to restore body weight and body composition towards its 'set' or 'preferred' value constitute adaptive changes in thermogenesis.

\section{Classical one-control system for adaptive thermogenesis}

Ever since studies into mechanisms of DIT started in 1960s [18], the focus of attention has been on the sympathetic nervous system (SNS), which, via its neurotransmitter norepinephrine, acts upon $\alpha$ - and $\beta$-adrenoceptors to influence heat production. It is now known that many other hormones (e.g., thyroid hormones, leptin, insulin, ghrelin) play a more permissive or facilitatory role in SNSmediated thermogenesis either by altering peripheral adrenergic responsiveness to the thermogenic effects of norepinephrine or by acting as peripheral signals for central control of SNS activity to peripheral tissues [19-21]. In fact, the interaction of many of the peripheral signals that control feeding behaviour and satiety-via inhibition of NPY/AgRP neurons and stimulation of POMC/CART neurons in the hypothalamus - also result in altered activity of the SNS and thermogenesis [21]. Of particular interest for SNS-mediated thermogenesis is the potential control by norepinephrine over biochemical mechanisms whose activation leads either to an increased use of ATP (e.g., ion pumping and substrate cycling) or to a higher rate of mitochondrial oxidation with poor coupling of ATP synthesis - the net result is an increase in heat production. But it was not until the demonstration that SNS activity in a variety of tissues is increased during overfeeding and decreased during starvation (a state of energy conservation) that the SNS was considered as a potentially pivotal efferent system in link between diet and thermogenesis [22]. More recent studies in mice lacking genes coding for all $\beta$-adrenoceptors $(\beta 1 \mathrm{AR}$, $\beta 2 \mathrm{AR}$, and $\beta 3 \mathrm{AR}$ ) have now firmly established the pivotal role for the SNS in the mediation of DIT [23]. In contrast to wild-type mice which resist obesity by activating DIT during overfeeding, mice lacking $\beta A R s$ (or $\beta$-less mice) are incapable of increasing thermogenesis and developing massive obesity despite similar food intake as in wild-type controls. Furthermore, the $\beta$-less mice are intolerant to cold exposure, thereby underscoring the overlapping role of SNS via $\beta$-AR signalling in the control of heat production in response to both diet and cold.

\subsection{The SNS-BAT-UCP axis}

It was indeed proposed some 25 years ago [24] that these two forms of thermogenesis have a common origin in brown adipose tissue (BAT). The thermogenic activity of BAT, which is abundant in small animals and human infants, is under SNS control and is primarily mediated in brown adipocytes by a mitochondrial protein (UCP) which allows protons to leak back across the inner mitochondrial membrane [25]. The resulting dissipation of the proton electrochemical gradient (a phenomenon referred to as (proton leak') allows substrate oxidation to occur without concomitant capture of some of the useful energy via the synthesis of ATP. The net effect during activation of UCP (by cold or diet) is that substrate oxidation is effectively uncoupled from phosphorylation with a resultant increase in heat production. Although in humans, several lines of evidence are consistent with an important role for SNS in the regulation of thermogenesis [22,26], the importance of BAT as a site of adaptive thermogenesis in the adult human proved to be elusive. Furthermore, mice lacking BAT-UCP do not become obese even on high fat diets [27], but like $\beta$ less mice, they are cold sensitive. Taken together, these 
studies underscore the central role of BAT-UCP in murine thermal regulation but may also suggest that SNS-BAT-UCP axis may not be the only important effector of DIT even in small mammals.

\subsection{SNS control of extra-BAT thermogenesis}

From which tissues/organs and by what molecular mechanisms, the extra heat due to DIT that might be produced still remains a mystery [28]. Several other tissues and organs (e.g., liver, kidneys, heart, pancreas) are activated by the SNS in response to diet (Table 2), but whether they contribute to DIT is unknown. A role for liver as a major site for DIT has been proposed on the basis that the increase in resting oxygen consumption of rats overfed on a cafeteria-like diet was considerably blunted by partial hepatectomy [29]. However, it is difficult, on the basis of these results, to delineate a role for liver as an effector site for DIT from that of a transducer of energy status [30], since partial hepatectomy may have impaired the transmission of signals from the liver to the 'true' effectors of DIT. As for skeletal muscle, evidence that SNS-mediated thermogenesis occurs in this tissue remains elusive. SNS activity in skeletal muscle of rats is unresponsive to starvation and overfeeding [31], and in adult humans (where BAT is scarce or quiescent), infusion of norepinephrine increases resting metabolic rate, but no detectable increase in thermogenesis occurred in forearm skeletal muscle [32]. Nonetheless, like in rodents, modulation of SNS activity by short-term underand overnutrition occurs in adult humans as judged from measurements of norepinephrine spillover in blood and urine [22], and furthermore, a low SNS activity has been shown to be a risk factor for weight gain in Pima Indians [33]. But the central issue of whether in humans, the subtle variations in DIT - which over months and years lead to obesity in some but weight maintenance in others-also reside in variations in SNS activity remains to be firmly established, just as the tissue/organ sites and molecular mechanisms that could account for this variability in metabolic efficiency.

Table 2

Heterogeneity in sympathetic nervous system (SNS) activity in response to diet and environmental temperature in the rat

\begin{tabular}{ccccccc}
\hline Stimulus & Heart & Pancreas & Liver & Kidney & $\begin{array}{l}\text { Brown } \\
\text { adipose } \\
\text { tissue }\end{array}$ & $\begin{array}{l}\text { Skeletal } \\
\text { muscle }\end{array}$ \\
\hline $\begin{array}{c}\text { Cold }\left(6{ }^{\circ} \mathrm{C}\right. \\
\left.\text { vs. } 22^{\circ} \mathrm{C}\right)\end{array}$ & $\uparrow$ & $\uparrow$ & 0 & 0 & $\uparrow$ & 0 \\
$\begin{array}{c}\text { Food (fed } \\
\text { vs. fasted) }\end{array}$ & $\uparrow$ & $\uparrow$ & $\uparrow$ & $\uparrow$ & $\uparrow$ & 0
\end{tabular}

The arrow up implies increased SNS activity in organs/tissues, as assessed by techniques of radiolabeled norepinephrine turnover; the zero symbol indicates no significant change. Note that the skeletal muscle is not recruited by the SNS in response to cold or diet, independently of the muscle type studied.

Source of references: Dulloo and Jacquet [96].

\subsection{Novel 'uncoupling' proteins}

The publications of two papers in 1996 prompted several laboratories to search for mitochondrial UCP and/or UCP homologues in skeletal muscle and other tissues, namely,

(i) the report by Nagase et al. [34] claiming that treatment with a $\beta 3$ agonist led to weight loss associated with expression of an uncoupling protein detected in skeletal muscle and white adipose tissue by Northern and Western probing for the BAT-UCP, and

(ii) the report of Rolfe and Brand [35] that the phenomenon of mitochondrial 'proton leak' is not unique to BAT, as originally thought, but also exists in tissues other than BAT, and could contribute as much as $25-$ $50 \%$ of the liver and skeletal muscle heat production at rest.

This search initially led to the discoveries of two new members of the 'uncoupling' protein family (UCP2 and UCP3) on the basis of their high sequence homology to BAT-UCP, renamed UCP1. Unlike UCP1, which is expressed only in BAT, UCP2 is expressed in all tissues so far examined (including organs involved in immunity or rich in macrophages), while UCP3 is expressed predominantly in skeletal muscles and BAT and to a lower extent in white adipose tissue and in the heart. These discoveries stimulated further the search for other UCP1-homologues and resulted in the cloning of Brain mitochondria carrier protein 1 (BMCP1) - also referred to as UCP5 - which is expressed in neural tissues, notably the brain, although its transcripts have also been reported in multiple human and mouse tissues, including in white and brown adipose tissue, liver, skeletal muscle, gut, kidney, heart, brain, and testis.

\subsection{UCP1-homologues: are they mediators of thermogenesis?}

Although a number of human studies have since linked polymorphisms of some of the UCP1-homologues (UCP2, UCP3) with obesity or with low rates of energy expenditure and/or fat oxidation [36-39], there is considerable uncertainties about their physiological roles, amid proposals that they might play a role in the mediation of thermogenesis, in the regulation of lipids as fuel substrate, in the control of insulin secretion, and/or in controlling the production of reactive oxygen species. These topics have been extensively reviewed during the past few years [40-49], but within the context of this review focusing on adaptive thermogenesis and fat metabolism, it is important to point out that it is debatable whether these UCP1-homologues have genuine uncoupling properties for the following reasons:

(i) Artefactual uncoupling: The overexpression of these UCP1-homologues in cell culture systems [50-52] and/or in mouse skeletal muscle [53] was reported to 
alter mitochondrial membrane potential in a direction that is consistent with uncoupling properties, but it has been argued that this uncoupling is the expression of artifacts arising from the disruption of mitochondrial membrane integrity [54-56].

(ii) Starvation paradox: An uncoupling role for UCP1homologues has also been proposed on the basis that fasting, which increases the expression of UCP2 and UCP3 in skeletal muscle, decreased its capacity to produce heat in response to the uncoupler FCCP, i.e., carbonyl-cyanide $p$-trifluoromethoxyphenylhydrazone [50]. This hypothesis of a UCP-mediated state of partial uncoupling in fasted muscle is, however, at odds to that expected for any putative mediator of thermogenesis in a well-established condition of energy conservation at the whole body level [41] and in the skeletal muscle [57]. In particular, fastinginduced increases in UCP2 and UCP3 expressions in skeletal muscle occur without changes in kinetics of proton conductance pathway in isolated mitochondria $[58,59]$ and without changes in the overall state of mitochondrial energy coupling in the hindlimb of awake animals, as assessed by noninvasive $13 \mathrm{C} / 31 \mathrm{P}$ NMR spectroscopic approaches [60].

(iii) High-fat feeding paradox: Similarly in humans, increasing fat in the diet leads to increased skeletal muscle UCP3 expression but not in mitochondrial uncoupling, as assessed by the lack of any changes in the rate of muscle phosphocreatine resynthesis during conditions of maximal flux through oxidative phosphorylation [61].

(iv) State 4 respiration controversies: It can always be argued that changes (or lack of it) in the gene or protein expression of UCP3 do not reflect changes in the activity of the protein. Indeed, the most direct evidence so far that UCP3 has physiologically relevant uncoupling properties rests à priori upon the report that state 4 respiration-which is often postulated to reflect basal proton leak respiration [62] - is lower in skeletal muscle from UCP3-knockout mice [63]. Both UCP3 gene expression and state 4 mitochondrial respiration were also found to be lowest in skeletal muscle from patients with the least weight losses than in those with the greatest weight losses, following a hypocaloric slimming therapy [64]. The implications of these findings [62-64] are, however, questionable following the failure to confirm the observations of a link between UCP3 and state 4 respiration (and/or proton leak) in another UCP3knockout mouse model $[65,66]$.

Whatever the explanation(s) for these discrepancies about the physiological significance of changes in UCP3 (gene vs. protein vs. activity) or state 4 respiration (in vitro vs. in vivo), the lack of correlation between UCP3 expression and state 4 respiration in response to dietary manipulations that alters adaptive thermogenesis $[67,68]$ considerably weakens the plausibility of a role for UCP3 in mediating adaptive changes in thermogenesis pertaining to weight regulation (see Table 3). To date, therefore, there is no convincing evidence that, under physiological conditions, UCP3 or other UCP1-homologues are mediators of thermogenesis.

\subsection{UCP1-homologues: a link with regulation of lipids as fuel substrate}

In the search for an alternative function for UCP1homologues, our reevaluation of data on UCP1, UCP2, and UCP3 with the state of knowledge about skeletal muscle and BAT metabolism during starvation [69] revealed that the only common association in both tissues was in parallel changes in their expressions and the utilization of lipids as fuel substrate (Table 4). In BAT, the decreases in gene expressions of UCP2 and UCP3 are in parallel to the decrease in utilization of lipids as metabolic fuel due to a general down-regulation of metabolic activity in this tissue, consequential to the suppressive effect of fasting on the SNSBAT-UCP1 axis. In the skeletal muscle, the increased UCP2 and UCP3 expressions are in line with the wellknown fasting-induced shift in substrate utilization in favour of lipids as the predominant metabolic fuel and hence allowing the sparing of glucose for organs/tissues with an obligatory requirement for glucose, notably the brain. Could it then be that the structural homology of UCP2 and UCP3 to UCP1 has been made with the wrong function of UCP1since the primary function of this uncoupling protein as a mediator of adaptive thermogenesis via mitochondrial proton leak has often been linked (by mechanisms that are poorly understood) to a putative secondary function as an anion/substrate transporter across the mitochondrial membranes [70,71]. This reevaluation presented in Table 4 constituted the backbone of the proposal that the primary function of UCP1-homologues in the skeletal muscle and BAT may somehow be involved actively or passively with

Table 3

Poor correlation between thermogenesis, basal proton leak, mitochondrial oxidative capacity, and UCP3 expression

\begin{tabular}{|c|c|c|c|c|c|}
\hline & \multirow{2}{*}{$\frac{\text { Overfeeding }}{\text { High fat }}$} & \multirow[t]{2}{*}{ Fasting } & \multirow[t]{2}{*}{ Semistarvation } & \multicolumn{2}{|c|}{ Refeeding } \\
\hline & & & & $\begin{array}{l}\text { Low } \\
\text { fat }\end{array}$ & $\begin{array}{l}\text { High } \\
\text { fat }\end{array}$ \\
\hline \multicolumn{6}{|l|}{ Whole-body } \\
\hline Thermogenesis & $\uparrow$ & $\downarrow$ & $\downarrow$ & $\downarrow$ & $\downarrow \downarrow$ \\
\hline \multicolumn{6}{|l|}{ Skeletal muscle } \\
\hline Thermogenesis & $?$ & $\downarrow$ & $?$ & $?$ & $?$ \\
\hline Proton leak & NS & NS & NS & $?$ & $?$ \\
\hline $\begin{array}{r}\text { State } 4 \text { or state } 3 \\
\text { mitorespiration }\end{array}$ & $\uparrow$ & $\downarrow$ & $\downarrow$ & NS & NS \\
\hline UCP3 mRNA & $\uparrow$ & $\uparrow$ & NS & $\downarrow$ & $\uparrow$ \\
\hline UCP3 protein & $\uparrow$ & $\uparrow$ & NS & NS & $\uparrow$ \\
\hline
\end{tabular}

Arrow up or down - an increase or a decrease, respectively; NS-no significance change; interrogation mark (?) - unknown. 
Table 4

A link between skeletal muscle UCP2/UCP3 gene expression and regulation of lipids as fuel substrate in response to fasting

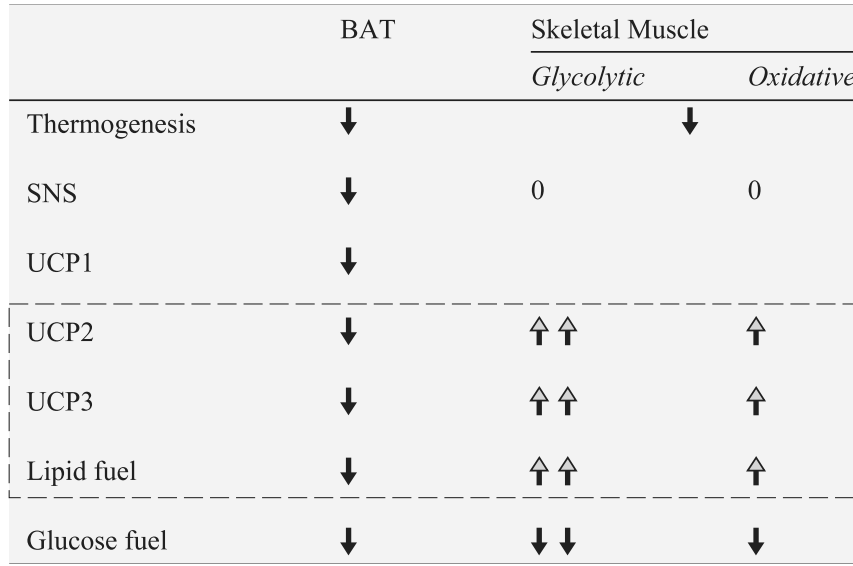

the regulation of lipids as fuel substrate rather than in the mediation of thermogenesis [69]. This contention has since been reinforced by numerous data in animals and in humans, the most compelling of which are that (i) changes in UCP2 and UCP3 gene expressions during fasting, in parallel to key regulators of lipid oxidation, are more pronounced in white muscles (predominantly fast glycolytic) than in red muscles (predominantly slow oxidative) and hence consistent with the greater dependency of slowoxidative muscles on lipids as fuel substrate, and the greater shift between glucose and lipids as fuel substrate in fastglycolytic muscles during fasting $[69,72,73]$, and that (ii) an increase in dietary fat leads to consistent elevations in UCP2 and UCP3 expressions in skeletal muscle and several other organs/tissues $[67,68,74,75]$. Furthermore, the associations found in humans between polymorphism in UCP2 or UCP3 with significant reductions in lipid oxidation [37-39] and that the short-insert isoform of UCP5/BMCP1 is correlated with lipid oxidation during physiological insulin infusion [76], are consistent with the proposal of a role for UCP1homologues in the regulation of lipids as fuel substrate.

\subsection{UCP1-homologues: are they transporters of fatty acids across mitochondria?}

The term 'lipids as fuel substrate' encompasses a multitude of control points that could theoretically be invoked in the handling of lipids in response to alterations in the flux of lipid substrates. It is not known whether UCP1-homologues are required at control points along the fatty acid $\beta$-oxidation pathway or whether they are involved in the prevention of lipotoxicity that may arise from excess fatty acid delivery and/or enhanced fatty acid oxidation. According to some authors [40], a role for UCP1homologues as transporters of fatty acids into the mitochondrial matrix (where fatty acid oxidation occurs) is unlikely because (a) the matrix lacks fatty acyl-CoA transferase activity and fatty acyl-CoA, and (b) the substrate for $\beta$ - oxidation has been shown not to be transported by UCP1 They also point out that UCP2 and UCP3 cannot mediate fatty acid transport, as it relates to $\beta$-oxidation on the grounds that fatty acid-carnitine carrier which transport fatty acids into the matrix has a low similarity ( $20 \%$ identity) with UCP1, UCP2, or UCP3. However, one wonders about the validity of rejecting carrier function solely on the basis of amino-acid identity to the carnitine carrier. A number of biochemical models have in fact been proposed in which these UCP1-homologues would operate as fatty-acid carriers across the mitochondria, and the putative function of UCP2 and/or UCP3 would be to export fatty acids out of the mitochondria when fatty acid supply or oxidation predominates, such as in the skeletal muscle during fasting and high-fat feeding [77-79]). Most of the proposed models have focused on UCP3, primarily because of the inability to detect UCP2 protein in organs/tissues known to be important sites of fat metabolism (skeletal muscle, heart, brown adipose tissue).

In the model proposed by Himms-Hagen and Harper [78], UCP3 is postulated to function as a transporter protein, but the energy cost for the operation of this cycle would be due mainly to the ATPase effect rather than to uncoupling via proton entry. According to their model, excess acyl-CoA within the mitochondria is hydrolyzed by a mitochondrial acyl-CoA thioesterase, yielding fatty acid anion and CoASH. The fatty acid anion is exported to the cytosol by being carried across the inner mitochondrial membrane by UCP3. The postulated function of the fatty acid export cycle would be to liberate CoASH for other uses at times of dependence on fatty acid oxidation as an energy source, i.e., in order for CoASH to participate in other reactions for which it is needed during fatty acid oxidation in the $\beta$ oxidation cycle and in the tricarboxylic acid cycle. The export of fatty acid anion thus permits continued rapid fatty acid oxidation in the face of an oversupply, while at the same time eliminating from the mitochondrion a potentially deleterious substrate, FFA, that it is unable to metabolize. Support for this hypothesis is drawn from the observation that thioesterase expression is increased in mice overexpressing UCP3 [80], and that there is a good correlation between thioesterase and UCP3 gene expression [81]. However, the various components of this model remain speculatory, and convincing evidence that a potential source of fatty acid anions in the mitochondrial matrix derived from the hydrolysis of acyl-CoA by an acyl-CoA thioesterase has not been reported.

In other models, UCP2 and/or UCP3 are postulated to be involved in the translocation of the fatty acid anions from the matrix side to the cytosolic side of the mitochondrial membrane $[42,71,79]$. The fatty acid anions would be protonated, and the UCP1-homologues would then 'flipflop' these neutral fatty acids back to the matrix side $[70,71,79]$, resulting in a lowering of the proton gradient and hence increased heat production. Within these models of fatty acid cycling, therefore, the UCP1-homologues 
would exert an uncoupling effect by being involved in translocating an excessive amount of fatty acid anions out of the mitochondrion. Support for this model is drawn from the observations of an elevated skeletal muscle UCP3 expression under conditions when one could expect cytosolic accumulation of free FFA due to diminished fatty acid oxidation, such as in patients who show multiple acyl-CoA dehydrogenase-deficiency [82] or after pharmacological inhibition using etomoxir $[83,84]$. These studies, however, do not provide evidence for a cause-effect relation between the up-regulation of UCP3 and mitochondrial export of FFA, since up-regulation of this UCP1 homologue (for some other undefined function) may simply be consequential to the cytosolic accumulation of fatty acids inherent in this hypothesis. Whatever the explanation for the findings that etomoxir up-regulates skeletal muscle UCP3 protein expression $[83,84]$, it must be underlined that treatment with etomoxir in fed and fasted animals failed to alter UCP3 (and UCP2) gene expression in muscles that are primarily fast-glycolytic or fast-oxidative-glycolytic $[85,86]$. A physiological role for UCP3 in the export of FFA when FFA supply exceeds fatty acid oxidation also seems inconsistent with changes in the expression of UCP3 in BAT under fasting conditions [69] or in BAT from mice with lacking UCP1 $[87,88]$. Under both these conditions when FFA supply greatly exceeds FFA oxidation in BAT, UCP3 in this tissue is either down-regulated or unaltered, respectively, rather than up-regulated, as predicted by this hypothesis.

\subsection{Is there a role for uncoupling proteins in fat metabolism and energy balance?}

The use of gene knockout (KO) technology to elucidate the role of uncoupling proteins in energy balance and substrate metabolism has, in general, been disappointing, inasmuch as mice lacking UCP1, UCP2, and UCP3 or both UCP1 and UCP3 do not become obese and have a phenotype similar to control mice; they do not appear to show major impairments in whole body resting metabolic rate, DIT, total energy expenditure, nor in substrate metabolism [27,63,89-91]. There are, however, many pitfalls in interpreting results from these gene $\mathrm{KO}$ and transgenic experiments. As emphasized by Williams and Wagner [92], unexpected consequences of genomic modifications are frequent, and the phenotype or lack of phenotype observed in any transgenic experiment is a function of both the planned genetic modification and of secondary responses of the organism to that perturbation. An example of this principle was demonstrated in the case of UCP1-knockout mice, which when reared at $22{ }^{\circ} \mathrm{C}$ (but not at $27^{\circ} \mathrm{C}$ ) are more resistant to obesity during high-fat feeding than their wild types [93]; the authors attribute this paradox to alternative, calorically more costly pathways of metabolism for maintaining body temperature in the absence of UCP1-mediated nonshivering thermogenesis. Thus, since the knocking out of genes for reasonably well-established functions often fail to reveal the expected impairment in these functions because of compensatory mechanisms (known or unknown), the failure of UCP2 or UCP3knockout mice to reveal major impairments in weight regulation via thermogenesis or substrate metabolism is not sufficient to reject the hypothesis that these UCP1homologues play a role in thermogenesis or lipid metabolism. Given the present state of knowledge, however, it can be concluded that there is no good evidence that UCP1homologues mediate thermogenesis or indeed have genuine uncoupling properties under physiological conditions. In contrast, there are strong associations between the expression of UCP3 (and to lesser extent UCP2 and UCP5/ $\mathrm{BMCP} 1$ ) and fat metabolism, but the nature of these associations remains undefined, and the physiological significance of these UCP1-homologues pertaining to the flux of lipids as fuel substrate across the cell remains elusive.

Within the context of molecular mechanisms underlying adaptive thermogenesis and fat metabolism, UCP1 seems to be the only genuine uncoupling protein that play a role in the mediation of thermogenesis and fat oxidation. In small mammals, its role in sympathetic control of thermoregulatory thermogenesis is well established, and its role in the control of DIT seems to be intimately linked, and secondary, to its role in thermal regulation. In humans, however, the notion that UCP1 is involved in DIT has been largely abandoned, although recent findings that children with UCP1 polymorphism (GG allele carriers) have lowered postprandial thermogenesis in response to a high-fat meal [94], raises the possibility that such UCP1-linked thermogenesis may have relevance for childhood obesity.

\section{Dual-control systems for adaptive thermogenesis}

Whatever the effector mechanisms (other than the SNSBAT-UCP axis) for sympathetic control of heat production, adaptive thermogenesis has in general been viewed as a 'rapid reaction' control system which functions as an 'attenuator' of energy imbalance. However, the common observation that after substantial weight losses or growth arrest, body fat is recovered at a disproportionately faster rate than that of lean tissue (Table 5) also suggests that, under these conditions of positive energy balance, adaptive thermogenesis can also be viewed as a 'slow-reaction' control system which functions specifically as an 'accelerator' of fat deposition, i.e., for 'catch-up fat' but not for catch-up of lean tissue [95]. How can both views about the dynamics of adaptive thermogenesis be reconciled?

\subsection{Concept of dual-control systems}

From a system physiology standpoint, the nature of the adaptive reduction in thermogenesis in response to starva- 
Table 5

Past reports of "Rapid" fat tissue recovery (catch-up fat) with lean tissue recovery "lagging behind"

\begin{tabular}{ll}
\hline Kornfeld and Schuller (1931) & - Emaciated patients in Vienna \\
Debray et al. (1946) & - Prisoners from concentration camps \\
Keys et al. (1950) & - Men after experimental starvation \\
Ashworth (1969) & - Infants/children recovering from \\
McLean and Graham (1980) & protein-energy malnutrition \\
Castilla-Serna et al. (1996) & \\
Barac-Nieto et al. (1979) & - Adults after substantial weight loss \\
Forbes et al. (1984) & (independently of protein level) \\
Mitchell and Truswell (1987) & - Anorectics regaining weight \\
Van Eys (1985) & - Cancer patients \\
Streat et al. (1987) & - Septic intensive care patients \\
Kotler et al. (1990) & - AIDS patients-parenteral nutrition \\
\hline
\end{tabular}

Source of references: Dulloo et al. [95].

tion and refeeding can be conceived to be constituted by two distinct control systems - as depicted in Fig. 2. One control system, which is a direct function of changes in the food energy supply, perhaps via the prompt alterations in insulin and leptin, responds relatively rapidly to the energy deficit. Its effector mechanisms are suppressed early during the course of starvation, and upon refeeding, they are restored relatively rapidly as a function of energy reavailability and are activated further if hyperphagia occurs during refeeding, which could hence account for increased DIT. Because the efferent limb of this control system-which is primarily under SNS control - is dictated not only by the dietary energy supply but also by a variety of other environmental factors such as diet composition, specific nutrient deficiencies, ambient temperature, psychological stress, etc., it is referred to as the nonspecific control of thermogenesis. By contrast, the other control system has a much slower timeconstant by virtue of its response only to signals arising from the state of depletion/repletion of body fat stores; it is therefore referred to as the control system operating through an adipose-specific control of thermogenesis [96]. The definitions of these two control systems underlying adaptive thermogenesis are thus made on the basis of their differential commands - either deriving solely from the state of adipose tissue fat stores or not.

\subsection{Evidence for two distinct control systems}

Direct evidence for the existence of an adipose-specific suppression of thermogenesis can be derived from wellcontrolled energy balance studies in laboratory animals regaining weight after semistarvation. Under conditions whereby the rehabilitated rats were pair-fed to weightmatched controls, the rate of protein deposition was found to be the same as in controls, but that of fat deposition was increased by more than twofold as a result of $10-15 \%$ lower energy expenditure during the first 2-3 weeks of isocaloric

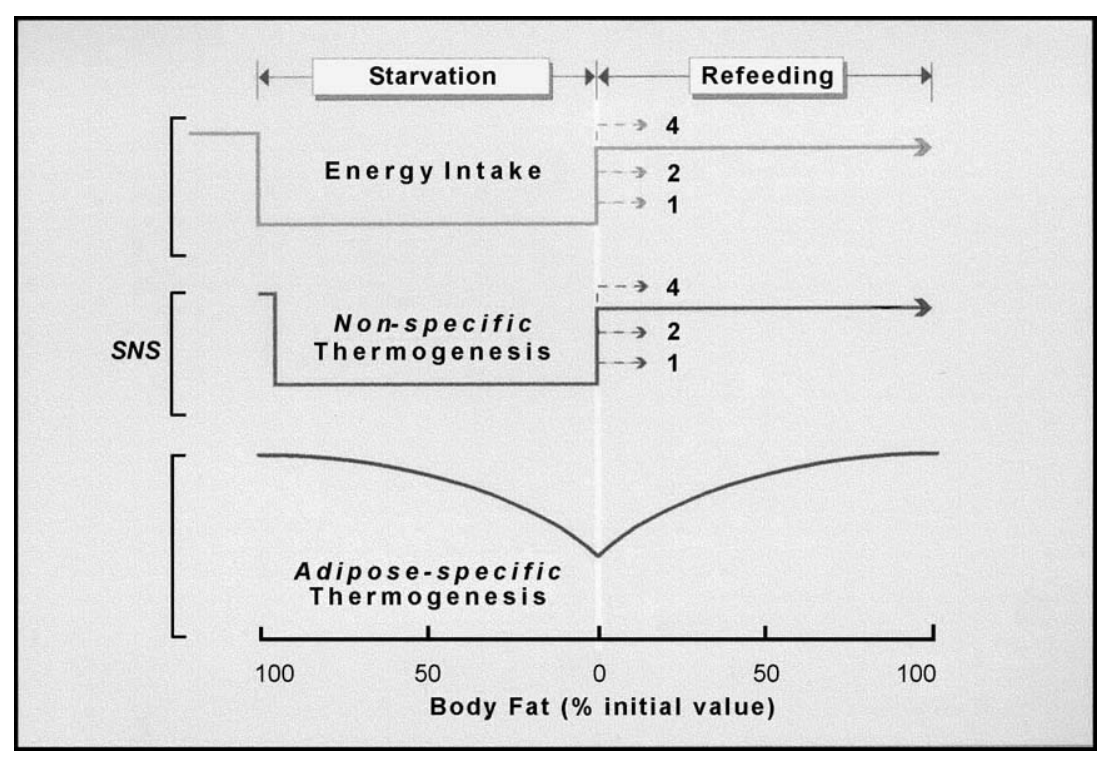

Fig. 2. Schematic representation of the concept of two distinct control systems underlying adaptive thermogenesis during prolonged starvation and subsequent refeeding. One control system, which is a direct function of changes in the food energy supply, responds relatively rapidly to the energy deficit. Its effector mechanisms are suppressed early during the course of starvation, and upon refeeding, they are restored relatively rapidly as a function of energy reavailability (levels 1-4) and are activated further if hyperphagia occurs during refeeding (level 4). Because the efferent limb of this control system is primarily under the control of the sympathetic nervous system (SNS) whose functional state is dictated by overlapping or interacting signals arising from a variety of environmental stresses, including food deprivation, deficiency of essential nutrients, excess energy intake, and exposure to cold or to infections, it is referred to as the nonspecific control of thermogenesis and is likely to occur primarily in organs/tissues with a high specific metabolic rate (e.g., liver, kidneys, BAT). The other control system, by contrast, is independent of the functional state of the SNS and has a much slower time-constant by virtue of its response only to signals arising from the state of depletion/repletion of the fat stores; it is therefore referred to as the control system operating through an adipose-specific control of thermogenesis. While suppression of this adipose-specific thermogenesis during starvation and during refeeding leads to energy conservation, the energy thus spared during refeeding is directed specifically at the replenishment of the fat stores, resulting in an accelerated fat recovery-a phenomenon that could contribute to the disproportionately rapid rate of fat relative to lean tissue recovery during refeeding after substantial fat stores depletion. Adapted from Dulloo and Jacquet [96]. 
refeeding $[96,97]$. A number of factors that could theoretically contribute to this difference in energetics between refed and controls (age difference, physical activity, feeding pattern) have been evaluated and shown to have a minimal impact on the difference in energy expenditure between the two groups [97]. Consequently, under conditions of our refeeding study, the lower energy expenditure in the refed than in the controls is essentially the energy spared as a result of sustained suppression of thermogenesis for the purpose of catch-up fat. The subsequent demonstrations [98] that when both refed and controls were pair-fed during exposure to cold (a state of markedly elevated sympathetic activation of thermogenesis) the refed animals still showed the capacity for energy conservation directed at catch-up fat (Fig. 3), suggested that the mechanisms underlying the adipose-specific suppression of thermogenesis are clearly distinct from sympathetic control of thermogenesis. Viewed in another way, the fact that during weight recovery suppressed adipose-specific thermogenesis (energy conservation) can coexist with enhanced SNS-mediated nonspecific thermogenesis (energy dissipation), whether in response to stimuli of cold [98], hyperphagia [99], protein-deficient diets [100], or infections [101], suggest that these two control systems have distinct effectors, with the adipose-specific control of thermogenesis occurring at sites other than those recruited by the SNS in response to diet and cold.

\subsection{Distinct effectors for dual-control systems}

Based upon tracer kinetic studies of norepinephrine turnover rates in various organs and tissues (Table 2), it could be postulated that the mechanisms underlying nonspecific (SNS) control of thermogenesis operate in the metabolically fast-tissues/organs (such as the liver, kidneys, heart and brown fat) and are rapidly restored upon food reavailability. By contrast, the mechanisms underlying the adipose-specific control of thermogenesis - and independently of the SNS - operate primarily in skeletal muscle, a tissue already known to be an important site of starvationinduced suppression of thermogenesis, as judged by studies of regional blood flow by microspheres coupled with measurements of arterial-venous oxygen consumption [57]. In other words, the control system underlying the adipose-specific control of thermogenesis could operate as a feedback loop between the adipose tissue fat stores and skeletal muscle. It could hence comprise a sensor(s) of the state of depletion of the fat stores, a signal(s) dictating the suppression of thermogenesis as a function of the state of depletion of the fat stores, and an effector system mediating adaptive thermogenesis in skeletal muscle [96]. Support for this contention can be derived from our recent studies [102], utilizing the hyperinsulinaemic euglycaemic clamp technique, showing that glucose utilization rate is diminished in skeletal muscle and elevated in adipose tissue during the phase of suppressed thermogenesis favouring catch-up fat in our rat model of weight recovery.

\subsection{A compartmental model}

An overall integration of the dual-control systems for adaptive thermogenesis in the regulation of body weight and body composition during a cycle of weight loss and weight recovery is discussed with the help of a schematic diagram presented in Fig. 4. This diagram (a) embodies previous findings that the control of body energy-partitioning between protein and fat is an individual characteristic, i.e., individuals vary in their partitioning characteristic $(\mathrm{Pc})$ between protein and fat during starvation (see Ref. [103] for review) and (b) takes into account the two distinct control systems for adaptive thermogenesis, which can operate independently of each other.

During starvation, the control of partitioning determines the relative proportion of protein and fat to be mobilized

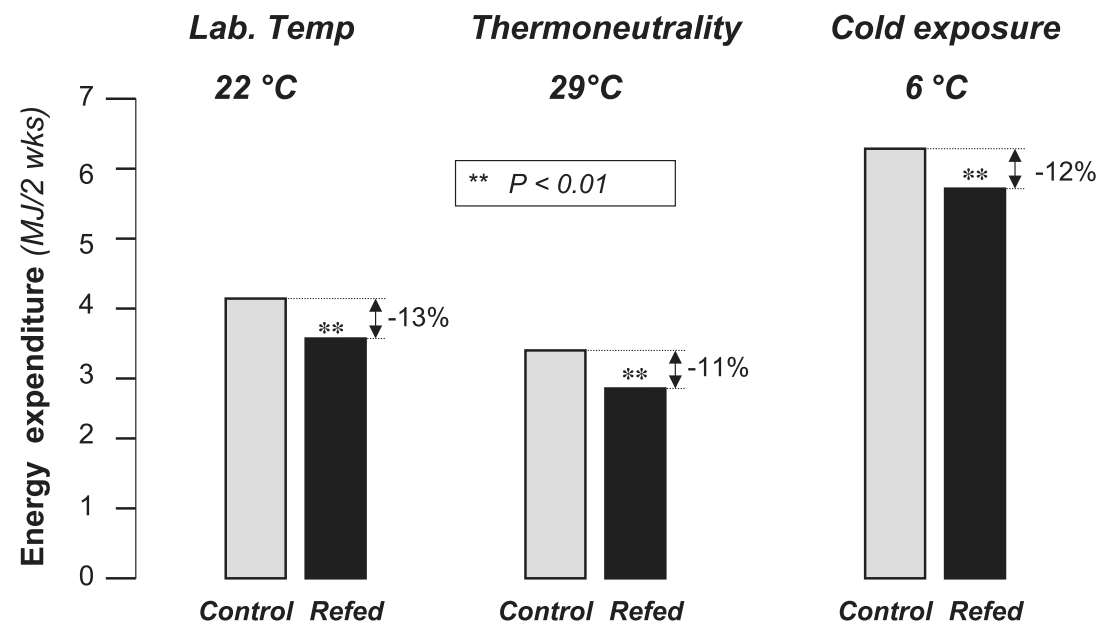

Fig. 3. Dissociation of suppressed thermogenesis favouring fat recovery during refeeding from sympathetic control of thermogenesis. Independently of environmental temperature, the refed animals pair-fed to their respective weight-matched controls show lower energy expenditure (by $11-13 \%$ ) and higher body fat gain. Drawn from data of Dulloo et al. [98]. 


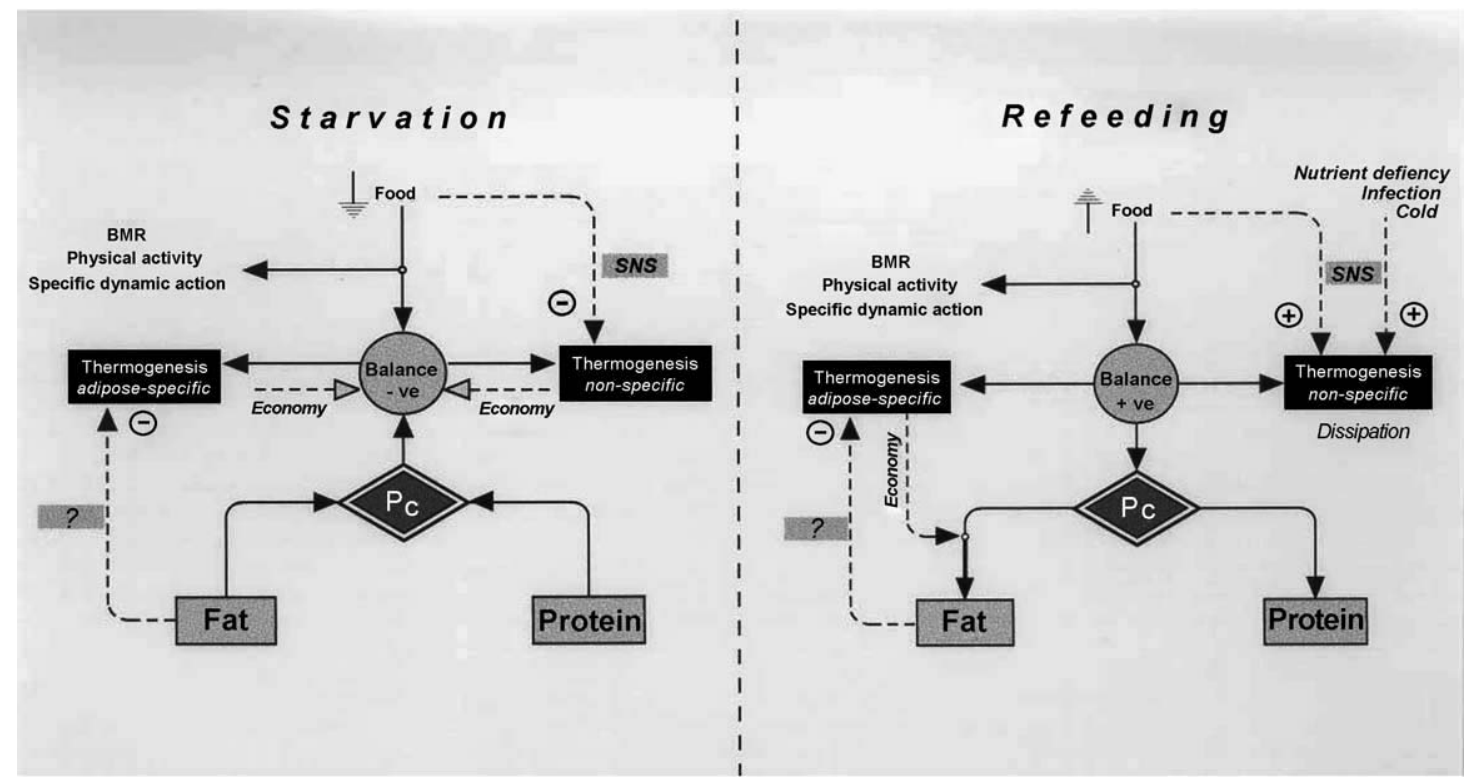

Fig. 4. Schematic representation of a compartmental model for the regulation of body weight and body composition during a cycle of weight loss (prolonged starvation) and weight recovery (refeeding). In this model, the two distinct control systems underlying adaptive thermogenesis-the nonspecific control and the adipose-specific control - are integrated with the more 'basal' control of partitioning between the body fat and protein compartments as determined by the partitioning characteristic (Pc) of the individual; see text for details. Adapted from Dulloo and Jacquet [96].

from the body as fuel (i.e., the individual's Pc), and the energy conserved due to suppressed thermogenesis is directed at reducing the energy imbalance, with the net result that there is a slowing down in the rate of protein and fat mobilization in the same proportion as defined by the Pc of the individual. Indeed, the fact that, in normal-weight humans and rodents, the fraction of fuel energy derived from protein (i.e., the $P$ ratio) remains relatively constant during the course of prolonged starvation $[104,105]$ implies that neither control systems underlying suppressed thermogenesis are directed at sparing specifically protein nor specifically fat but at sparing both protein and fat compartments. During starvation, therefore, the functional role of both control systems underlying suppressed thermogenesis is to reduce the overall rate of fuel utilization (i.e., for energy conservation directed at sparing both lean and fat tissues).

During refeeding, the control of partitioning operates in such a way that protein and fat are deposited in the same relative proportion as determined by the Pc of the individual during starvation, and the increased availability of food leads to the rapid removal of suppression upon the nonspecific (SNS-mediated) control of thermogenesis. By contrast, the suppression of thermogenesis under adiposespecific control is only slowly relieved as a function of fat recovery, such that the energy that continues to be spared is directed specifically at the replenishment of the fat stores. The net effect, as previously demonstrated using both statistical and numerical approaches in our reanalysis [106] of human data from the Minnesota Experiment of semistarvation and restricted refeeding [107], and substantiated by animal studies [97-99], is that fat is deposited in excess of that determined by the Pc of the individual. This would account, at least in part, for the specific acceleration of fat deposition and hence the disproportionate rate of fat relative to lean tissue recovery.

\subsection{Biological significance}

Such an adaptive phenomenon that accelerates the restitution of fat stores rather than to divert the energy saved towards compensatory increases in body protein synthesis (an energetically costly process) would have survival value in ancestral famine-and-feast lifestyle. By virtue of the fact that body fat has a greater energy density and a lower energy cost of synthesis/maintenance than protein, it would provide the organism with a greater capacity to rapidly rebuild an efficient energy reserve and hence to optimize its survival capacity in the face of recurrent shortage of food. But equally important for the survival of mammals during weight loss and weight recovery is the need to retain the capacity to increase heat production (i.e., thermogenesis) in response to a number of other environmental stresses, namely, (a) for increased thermoregulatory needs in cold environments, (b) for the generation of fever during exposure to infections, or (c) for increased heat production as an adaptation to nutrientdeficient diets.

The necessity to increase DIT in the face of nutrientdeficient diets probably had evolutionary survival advantage of 'homeostatic waste' because it enables individuals to overeat relatively large quantities of poor quality food in order to obtain essential nutrients without the deposition of excess nonessential energy as fat. Excessive weight gain 
would be a hindrance to optimal locomotion, hunting capabilities and the ability to fight or flee. Stock [4] has proposed that DIT may have evolved as a means of regulating the metabolic supply of essential nutrients (protein, minerals, vitamins) with only a secondary role in regulating energy balance and body weight. Whatever the exact functional significance of DIT, however, it is clear that, in a context of weight recovery, an elevated efficiency catch-up fat can be shown to persist even under conditions of hypermetabolism (a net increase in thermogenesis) induced by hyperphagia or nutrient-deficient diets $[99,100]$.

To explain this apparent paradox, the model presented in Fig. 4 provides a structural framework that illustrates how suppressed adipose-specific thermogenesis resulting in enhanced fat deposition during refeeding (and postulated to occur in the skeletal muscle) could persist under conditions when the nonspecific control of thermogenesis is activated in organs/tissues recruited by the SNS (liver, kidneys, heart, BAT). These differentially regulated control systems for thermogenesis may thus have arisen during the course of mammalian evolution as dual-adaptive processes that can satisfy the need for energy conservation during weight loss or for catch-up fat during weight recovery, even under environmental stresses when SNS-mediated activation of heat production has equally important survival values.

\subsection{Application to a longitudinal human study of weight fluctuations}

The existence and operation of this dual-control systems for adaptive thermogenesis is consistent with the temporal changes of BMR and body composition during the unique longitudinal study of semistarvation, refeeding, and subsequent overfeeding in men from the Minnesota Experiment [107]. The pattern of changes in food intake and body weight, together with kinetics of altered thermogenesis (assessed as changes in BMR adjusted for fat-free mass $[\mathrm{FFM}]$ and fat mass and expressed as a percentage of baseline BMR value), is presented in Fig. 5.

During the phase of weight loss, the operation of the two control systems for adaptive thermogenesis is suggested by the fact that reduction in thermogenesis is biphasic in nature, with an initial rapid reduction in adjusted BMR at week 4, corresponding to $10 \%$ of baseline BMR, followed by a slower reduction in adjusted BMR, corresponding to $20 \%$ and $25 \%$ of baseline BMR at weeks 20 and 24, respectively $[95,96,108]$. At the latter time-points during starvation (at S20 and S24), the magnitude of reduced adjusted BMR was found to be associated with the reduction in fat mass [108] - i.e., the greater the degree of depletion of the fat stores, the greater the suppression of thermogenesis.

During the phase of weight recovery, the operation of the two control systems for thermogenesis is also suggested by the following:

(a) the relation between the degree of depletion of fat stores and suppressed (adipose-specific) thermogenesis persists at week 12 of restricted refeeding [108], at which time-point (R12) the mean adjusted BMR is still about $10 \%$ below baseline BMR level, the body fat is $80 \%$ recovered, while body weight and FFM recoveries are less than $50 \%$, and

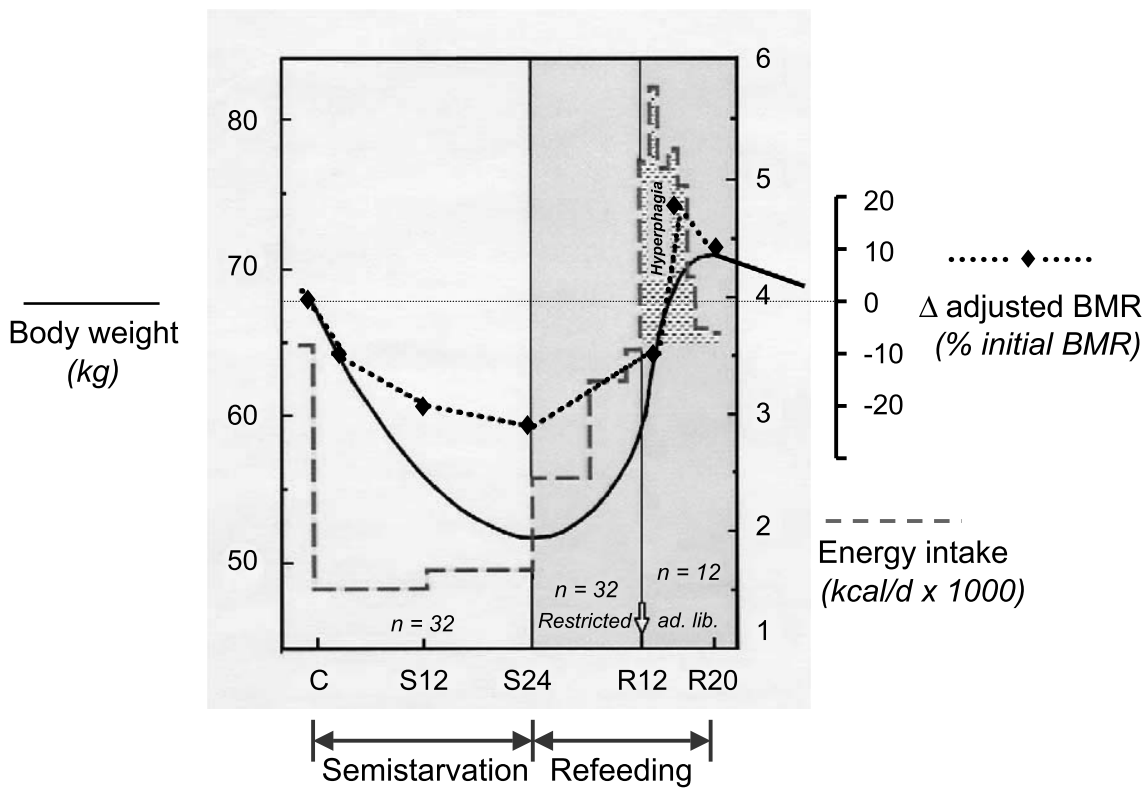

Fig. 5. Pattern of changes in body weight, food intake, and adaptive thermogenesis during the various phases of the longitudinal 'Minnesota Experiment' of human semistarvation and refeeding. The changes in adaptive thermogenesis at the various time-points are assessed as changes in basal metabolic rate (BMR) after adjusting for changes in fat-free mass (FFM) and fat mass and expressed as a percentage of the baseline (control, C) BMR level. C-end of control (baseline) period; S12 and S24 - week 12 and week 24 of semistarvation, respectively; R12 and R20-week 12 and week 20 after onset of refeeding. Drawn from data of Keys et al. [107] and Dulloo and Jacquet [108]. 
(b) after withdrawal of the dietary restriction during the subsequent period of ad libitum refeeding, the development of hyperphagia is accompanied by a prompt (perhaps SNS-mediated nonspecific) increase in thermogenesis, as judged by increases in adjusted BMR corresponding to about $20 \%$ of baseline BMR at week 14 of refeeding.

It is also noticeable that by week 20 after the onset of refeeding (at R20), when FFM has been almost 100\% recovered and body fat had overshot baseline (prestarvation) level by $>70 \%$ [109] — a phenomenon that Keys et al. [107] referred to as 'poststarvation obesity'-the adjusted BMR remains significantly higher (by about $10 \%$ ) above the baseline BMR despite the fact that hyperphagia is no longer present. This postoverfeeding sustained elevation of thermogenesis, also observed in laboratory rats $[110,111]$, is consistent with a feedback mechanism existing between thermogenesis and body fat-i.e., the result of an activated adipose-specific control of thermogenesis, which may well have contributed to the subsequent slow return of body weight towards the baseline level after the phase of fat overshooting.

It should be noted that this study only enabled analysis of adaptive changes in thermogenesis in the BMR compartment, since Keys et al. [107] did not measure the thermic effect of food nor the energy cost of physical activity. They noted, however, that there was a profound decrease in SPA of the subjects, particularly during weeks S12 and S24 of semistarvation.

\section{Concluding remarks}

Despite major caveats in our understanding of organ sites and molecular mechanisms for adaptive thermogenesis, it is nonetheless clear that the two control systems operating through adjustments in thermogenesis could play a crucial role in attenuating and correcting deviations of body weight from its 'set' or 'preferred' value. The extent to which these adjustments through adaptive thermogenesis are brought about is dependent upon the environment (e.g., diet composition) and is highly variable from one individual to another largely because of variations in the genetic make-up among individuals. In societies where food is plentiful all year round and physical activity demands are low, the resultant subtle variations among individuals in adaptive thermogenesis can, in dynamic systems and over the longterm, be important in determining long-term constancy of body weight in some and in provoking the drift towards obesity in others. The greatest challenges nowadays are to find or design the experimental conditions that are the most likely to unravel the molecular-physiological processes underlying each of these control systems. The components of the control system underlying the adipose-specific suppression of thermogenesis, namely, its sensor(s), sig- nal(s), and effector(s), can certainly be studied 'in isolation' from the other control systems regulating body composition [96] but within the type of constraints that can only be imposed in animal experimentation. Furthermore, subtle differences among humans in their capacity for nonspecific control of thermogenesis in response to diet (i.e., in elevated DIT) - while of quantitative importance in their different susceptibilities to obesity when cumulated over months to years - are unlikely to be picked up by conventional techniques during the relative short durations of human experimentation. It may prove necessary to simulate the appropriate unbalanced dietary conditions (e.g., low-protein overfeeding) under which DIT is recruited $[4,5]$ in order to unmask some of the genetic and metabolic machinery responsible for human variability in thermogenesis.

\section{Acknowledgements}

Supported by the Swiss National Science Foundation (grant \# 3200B0-102156).

\section{References}

[1] Garrow J. Energy balance and obesity in man, North Holland. Amsterdam: Elsevier; 1974.

[2] Payne PR, Dugdale AE. Mechanisms for the control of body weight. Lancet 1977;8011:583-6.

[3] Leibel RL, Rosenbaum M, Hirsch J. Changes in energy expenditure resulting from altered body weight. N Engl J Med 1995;332:621-8.

[4] Stock MJ. Gluttony and thermogenesis revisited. Int J Obes 1999;23:1105-17.

[5] Dulloo AG, Jacquet IJ. Low-protein overfeeding: a tool to unmask susceptibility to obesity in humans. Int J Obes 1999;23:1118-21.

[6] Bouchard C, Tremblay A, Desprès JP, Nadeau A, Lupien PJ, Thiérault G, et al. The response to long-term overfeeding in identical twins. N Engl J Med 1990;322:1477-82.

[7] Hainer V, Stunkard AJ, Kunesova M, Parizkova J, Stich V, Allison DB. A twin study of weight loss and metabolic efficiency. Int J Obes 2001;25:533-7.

[8] Girardier L, Clark MG, Seydoux J. Thermogenesis associated with spontaneous activity: an important component of thermoregulatory needs in rats. J Physiol 1995;488:779-87.

[9] Weyer C, Walford RL, Harper IT, Milner M, MacCallum T, Tataranni PA, et al. Energy metabolism after 2 y of energy restriction: the biosphere 2 experiment. Am J Clin Nutr 2000;72:946-53.

[10] Ravussin E, Lillioja S, Anderson TE, Christin L, Bogardus C. Determinants of 24-hour energy expenditure in man: methods and results using a respiratory chamber. J Clin Invest 1986;78:1568-78.

[11] Miller DS, Mumford P, Stock MJ. Gluttony 2. Thermogenesis in overeating man. Am J Clin Nutr 1967;20:1223-9.

[12] Levine JA, Eberhardt NL, Jensen MD. Role of nonexercise activity thermogenesis in resistance to fat gain in humans. Science 1999;283:212-4.

[13] Rosenbaum M, Vandenborne K, Goldsmith R, Simoneau JA, Heymsfield S, Joanisse DR, et al. Effects of experimental weight perturbation on skeletal muscle work efficiency in human subjects. Am J Physiol 2003;285:R183-92.

[14] Weigle BS, Brunzell J. Assessment of energy expenditure in ambulatory reduced-obese subjects by techniques of weight stabilization and exogenous weight replacement. Int J Obes 1990;14:69-77. 
[15] Doucet E, Imbeault P, St-Pierre S, Almeras N, Mauriege P, Despres $\mathrm{JP}$, et al. Greater than predicted decrease in energy expenditure during exercise after body weight loss in obese men. Clin Sci (Lond) 2003;105:89-95.

[16] Kulkarni R, Shetty P. Net mechanical efficiency during stepping in chronically energy deficient human subjects. Ann Hum Biol 1992;19:421-5.

[17] Richard D, Rivest S. The role of exercise in thermogenesis and energy balance. Can J Physiol Pharm 1989;67:402-9.

[18] Stirling JL, Stock MJ. Metabolic origins of thermogenesis induced by diet. Nature 1968;220:801-2.

[19] Rothwell NJ, Saville ME, Stock MJ. Sympathetic and thyroid influences on metabolic rate in fed, fasted and refed rats. Am J Physiol 1982;243:R339-46.

[20] Rothwell NJ, Stock MJ. Insulin and thermogenesis. Int J Obes 1988;12:93-102.

[21] Flier JF. Obesity wars: molecular progress confronts an expanding epidemic. Cell 2004;116:337-50.

[22] Landsberg L, Saville ME, Young JB. The sympathoadrenal system and regulation of thermogenesis. Am J Physiol 1984;247:E181-9.

[23] Bachman ES, Dhillon H, Zhang CY, Cinti S, Bianco AC, Kobilka $\mathrm{BK}$, et al. BetaAR signaling required for diet-induced thermogenesis and obesity resistance. Science 2002;297:843-5.

[24] Rothwell NJ, Stock MJ. A role for brown adipose tissue in dietinduced thermogenesis. Nature 1979;281:31-5.

[25] Cannon B, Nedergaard J. Brown adipose tissue: function and physiological significance. Physiol Rev 2004;84:277-359.

[26] Astrup A, MacDonald IA. Sympathoadrenal system and metabolism. In: Bray GA, Bouchard C, James WPT, editors. Handbook of obesity. New York: Marcel Dekker; 1988. p. 491-511.

[27] Enerbäck S, Jacobsson A, Simpson EM, Guerra C, Yamashita H, Harper ME, et al. Mice lacking mitochondrial uncoupling protein are cold sensitive but not obese. Nature 1997;387:90-4.

[28] Dulloo AG. A sympathetic defense against obesity. Science 2002;297:780-1.

[29] Ma SWY, Nadeau BE, Foster DO. Evidence for the liver as the major site of the diet-induced thermogenesis of rats fed a 'cafeteria' diet. Can J Physiol Pharm 1987;65:1802-4.

[30] Langhans W. Role of the liver in the control of glucose-lipid utilization and body weight. Curr Opin Clin Nutr Metab Care 2003;6:449-55.

[31] Dulloo AG, Young JB, Landsberg L. Sympathetic nervous system responses to cold exposure and diet in rat skeletal muscle. Am J Physiol 1988;255:E180-8.

[32] Kurpad AV, Khan K, Calder AG, Elia M. Muscle and whole body metabolism after norepinephrine. Am J Physiol 1994;266:E877-84.

[33] Tataranni PA, Young JB, Bogardus C, Ravussin E. A low sympathoadrenal activity is associated with body weight gain and development of central adiposity in Pima Indian men. Obes Res 1997;5:341-7.

[34] Nagase I, Yoshida T, Kumamoto K, Umekawa T, Sakane N, Nikami $\mathrm{H}$, et al. Expression of uncoupling protein in skeletal muscle and white adipose tissue of obese mice treated with thermogenic $\beta_{3}$ adrenergic agonist. J Clin Invest 1996;97:2898-904.

[35] Rolfe DF, Brand MD. Contribution of mitochondrial proton leak to skeletal muscle respiration and to standard metabolic rate. Am J Physiol 1996;271:1380-9.

[36] Walder K, Norman RA, Hanson RL, Schrauwen P, Neverova M, Jenkinson $\mathrm{CP}$, et al. Association between uncoupling protein polymorphisms (UCP2-UCP3) and energy metabolism/obesity in Pima Indians. Hum Mol Genet 1998;7:1431-5.

[37] Argyropoulos G, Brown AM, Willi SM, Zhu J, He Y, Reitman M, et al. Effects of mutations in the human uncoupling protein 3 gene on the respiratory quotient and fat oxidation in severe obesity and type 2 diabetes. J Clin Invest 1998;102:1345-51.

[38] Astrup A, Toubro S, Dalgaard LT, Urhammer SA, Sorensen TIA, Pedersen O. Impact of the $\mathrm{v} / \mathrm{v} 55$ polymorphism of the uncoupling protein 2 gene on 24-h energy expenditure and substrate oxidation. Int J Obes 1999;23:1030-4.

[39] Le Fur S, Le Stunff C, Dos Santos C, Bougnères P. The common $-866 \mathrm{G} / \mathrm{A}$ polymorphism in the promoter of uncoupling protein 2 is associated with increased carbohydrate and decreased lipid oxidation in juvenile obesity. Diabetes 2004;53:235-9.

[40] Boss O, Hagen T, Lowell BB. Uncoupling proteins 2 and 3: potential regulators of mitochondrial energy metabolism. Diabetes 2000;49:143-56.

[41] Dulloo AG, Samec S. Uncoupling proteins: their roles in adaptive thermogenesis and substrate metabolism reconsidered. Br J Nutr 2001;86:123-39.

[42] Jezek P. Possible physiological roles of mitochondrial uncoupling proteins-UCPn. Int J Biochem Cell Biol 2002;34:1190-206.

[43] Argyropoulos G, Harper ME. Uncoupling proteins and thermoregulation. J Appl Physiol 2002;92:2187-98.

[44] Schrauwen P, Hesselink M. UCP2 and UCP3 in muscle controlling body metabolism. J Exp Biol 2002;205:2275-85.

[45] Argiles JM, Busquets S, Lopez-Soriano FJ. The role of uncoupling proteins in pathophysiological states. Biochem Biophys Res Commun 2002;293:1145-52.

[46] Erlanson-Albertsson C. The role of uncoupling proteins in the regulation of metabolism. Acta Physiol Scand 2003;178:405-12.

[47] Nedergaard J, Cannon B. The 'novel' 'uncoupling' proteins UCP2 and UCP3: what do they really do? Pros and cons for suggested functions. Exp Physiol 2003;88:65-84.

[48] Nagy TR, Blaylock ML, Garvey T. Role of UCP2 and UCP3 in nutrition and obesity. Nutrition 2004;20:139-44.

[49] Rousset S, Alves-Guerra MC, Mozo J, Miroux B, Cassard-Doulcier $\mathrm{F}$, Bouillaud $\mathrm{F}$, et al. The biology of mitochondrial uncoupling proteins. Diabetes 2004;53(Suppl 1):S130-5.

[50] Boss O, Samec S, Kuhne F, Bijlenga P, Assimacopoulos-Jeannet F, Seydoux $\mathrm{J}$, et al. Uncoupling protein-3 expression in rodent skeletal muscle is modulated by food intake but not by changes in environmental temperature. J Biol Chem 1998;273:5-8

[51] Sanchis D, Fleury C, Chomiki N, Goubern M, Huang Q, Neverova $\mathrm{M}$, et al. BMCP1, a novel mitochondrial carrier with high expression in the central nervous system of humans and rodents, and respiration uncoupling activity in recombinant yeast. J Biol Chem 1998;273: 34611-5.

[52] Zhang CY, Hagen T, Mootha V, Slieker LJ, Lowell BB. Assessment of uncoupling activity of uncoupling protein 3 using a yeast heterologous expression system. FEBS Lett 1999;449:129-34.

[53] Clapham JC, Arch JR, Chapman A, Haynes A, Lister C, Moore GBT, et al. Mice overexpressing human uncoupling protein 3 in skeletal muscle are hyperphagic and lean. Nature 2000;406:415-8.

[54] Stuart JA, Harper JA, Brindle KM, Jekabsons MB, Brand MD. Physiological levels of mammalian uncoupling protein 2 do not uncouple yeast mitochondria. J Biol Chem 2001;276:18633-9.

[55] Harper JA, Stuart JA, Jekabsons MB, Roussel D, Brindle KM, Dickinson K. Artifactual uncoupling by uncoupling protein 3 in yeast mitochondria at the concentrations found in mouse and rat skeletal-muscle mitochondria. Biochem J 2002;361(Pt 1):49-56.

[56] Brand MD, Pamplona R, Portero-Otin M, Requena JR, Roebuck SJ, Buckingham JA, et al. Oxidative damage and phospholipid fatty acyl composition in skeletal muscle mitochondria from mice underexpressing or overexpressing uncoupling protein 3. Biochem J 2002;368:597-603

[57] Ma SWY, Foster DO. Starvation-induced changes in metabolic rate, blood flow, and regional energy expenditure in rats. Can J Physiol Pharm 1986;64:1252-8.

[58] Cadenas S, Buckingham JA, Samec S, Seydoux J, Din N, Dulloo AG, et al. UCP2 and UCP3 rise in starved rat skeletal muscle but not mitochondrial proton conductance is unchanged. FEBS Lett 1999;462:257-60.

[59] Iossa S, Lionetti L, Mollica MP, Crescenzo R, Botta M, Samec S, et al. Differences in proton leak kinetics, but not in UCP3 protein 
content, in subsarcolemmal and intermyofibrillar skeletal muscle mitochondria from fed and fasted rats. FEBS Lett 2001;505:53-6.

[60] Jucker BM, Ren J, Dufour S, Cao X, Previs SF, Cadman KS, et al. ${ }^{13} \mathrm{C} /{ }^{31} \mathrm{P}$ NMR assessment of mitochondrial energy coupling in skeletal muscle of awake fed and fasted rats: relationship with uncoupling protein 3 expression. J Biol Chem 2000;275:39279-86.

[61] Hesselink MK, Greenhaff PL, Constantin-Teodosiu D, Hultman E, Saris WH, Nieuwlaat R, et al. Increased uncoupling protein 3 content does not affect mitochondrial function in human skeletal muscle in vivo. J Clin Invest 2003;111:479-86.

[62] Lanni A, Beneduce L, Lombardi A, Moreno M, Boss O, Muzzin P, et al. Expression of uncoupling protein-3 and mitochondrial activity in the transition from hypothyroid to hyperthyroid state in rat skeletal muscle. FEBS Lett 1999;12:250-4.

[63] Vidal-Puig AJ, Grujic D, Zhang CY, Hagen T, Boss O, Ido Y, et al. Energy metabolism in uncoupling protein 3 gene knockout mice. J Biol Chem 2000;275:16258-66.

[64] Harper ME, Dent R, Monemdjou S, Bezaire V, Van Wyck L, Wells $\mathrm{G}$, et al. Decreased mitochondrial proton leak and reduced expression of uncoupling protein 3 in skeletal muscle of obese diet-resistant women. Diabetes 2002;51:2459-66.

[65] Bézaire V, Hofmann W, Kramer JKG, Kozak L, Harper ME. Effects of fasting on muscle mitochondrial energetics and fatty acid metabolism in Ucp3(-/-) and wild-type mice. Am J Physiol 2001;281:E975-82.

[66] Cadenas S, Ectay KS, Harper JA, Jekabsons MB, Buckingham JA, Grau E, et al. The basal proton conductance of skeletal muscle mitochondria from transgenic mice overexpressing or lacking uncoupling protein-3. J Biol Chem 2002;277:2773-8

[67] Iossa S, Mollica MP, Lionetti L, Crescenzo R, Botta M, Samec S, et al. Skeletal muscle mitochondrial efficiency and uncoupling protein 3 in overeating rats with increased thermogenesis. Pflugers Arch 2002;445:431-6.

[68] Crescenzo R, Mainieri D, Solinas G, Montani JP, Seydoux J, Liverini $\mathrm{G}$, et al. Skeletal muscle mitochondrial oxidative capacity an uncoupling protein 3 are differently influenced by semistarvation and refeeding. FEBS Lett 2003;544:138-42.

[69] Samec S, Seydoux J, Dulloo AG. Role of UCP homologues in skeletal muscles and brown adipose tissue: mediators of thermogenesis or regulators of lipids as fuel substrate? FASEB J 1998; $12: 715-24$

[70] Garlid KD, Orosz DE, Modriansky M, Vassanelli S, Jezek P. On the mechanism of fatty acid-induced proton transport by mitochondrial protein. J Biol Chem 1996;271:2615-20.

[71] Jezek P, Engstova H, Zackova M, Vercesi AE, Costa AD, Arruda P, et al. Fatty acid cycling mechanism and mitochondrial uncoupling proteins. Biochim Biophys Acta 1998;1365:319-27.

[72] Samec S, Seydoux J, Dulloo AG. Inter-organ signaling between adipose tissue metabolism and skeletal muscle UCP homologues: is there a role for circulating FFA? Diabetes 1998;47:1693-8.

[73] Samec S, Seydoux J, Russell AP, Montani JP, Dulloo AG. Skeletal muscle heterogeneity in fasting-induced upregulation of genes encoding UCP2, UCP3, PPAR $\gamma$ and key enzymes of lipid oxidation. Eur J Physiol 2002;445:80-6.

[74] Samec S, Seydoux J, Dulloo AG. Post-starvation gene expression of skeletal muscle UCP2 and UCP3 in response to dietary fat levels and fatty acid composition: a link with insulin resistance. Diabetes 1999;48:436-41.

[75] Schrauwen P, Hoppeler H, Billeter R, Bakker AHF, Pendergast DR. Fiber type dependent upregulation of human skeletal muscle UCP2 and UCP3 mRNA expression by high-fat diet. Int J Obes 2001;25: 449-56.

[76] Yang X, Pratley RE, Tokraks S, Tataranni PA, Permana PA. UCP5/ $\mathrm{BMCP} 1$ transcript isoforms in human skeletal muscle: relationship of the short-insert isoform with lipid oxidation and resting metabolic rates. Mol Genet Metab 2002;75:69-373.
[77] Simoneau JA, Kelley DE, Neverova M, Warden CH. Overexpression of muscle uncoupling protein-2 in human obesity associated with reduced muscle lipid utilization. FASEB J 1998;12:1739-45.

[78] Himms-Hagen J, Harper ME. Physiological role of UCP3 may be export of fatty acids from mitochondria when fatty acid oxidation predominates: an hypothesis. Proc Soc Exp Biol Med 2001;226:78-84.

[79] Schrauwen P, Saris WH, Hesselink MK. An alternative function for human uncoupling protein 3 as a mitochondrial fatty acid anion exporter. FASEB J 2001;16:1688-90.

[80] Moore GB, Himms-Hagen J, Harper ME, Clapham JC. Overexpression of UCP3 in skeletal muscle of mice results in increased expression of mitochondrial thioesterase mRNA. Biochem Biophys Res Commun 2001;283:785-90.

[81] Clapham JC, Coulthard VH, Moore GB. Concordant mRNA expression of UCP3, but not UCP2, with mitochondrial thioesterase-1 in brown adipose tissue and skeletal muscle in $\mathrm{db} / \mathrm{db}$ diabetic mice. Biochem Biophys Res Commun 2001;287:1058-62.

[82] Russell AP, Schrauwen P, Somm E, Gastaldi G, Hesselink MK, Schaart G, et al. Decreased fatty acid beta-oxidation in riboflavinresponsive, multiple acylcoenzyme A dehydrogenase-deficient patients is associated with an increase in uncoupling protein-3. J Clin Endocrinol Metab 2003;88:5921-6.

[83] Schrauwen P, Hinderling V, Hesselink MK, Schaart G, Kornips E, Saris WH, et al. Etomoxir-induced increase in UCP3 supports a role of uncoupling protein 3 as a mitochondrial fatty acid anion exporter. FASEB J 2002;16:1688-90.

[84] Schrauwen P, Hoeks J, Schaart G, Kornips E, Binas B, Van De Vusse GJ, et al. Uncoupling protein 3 as a mitochondrial fatty acid anion exporter. FASEB J 2003;17:2272-4.

[85] Samec S, Seydoux J, Dulloo AG. Skeletal muscle UCP3 and UCP2 in response to inhibition of free fatty acid flux through mitochondrial B-oxidation. Eur J Physiol 1999;438:452-7.

[86] Dulloo AG, Samec S, Seydoux J. Uncoupling protein 3 and fatty acid metabolism. Biochem Soc Trans 2001;29:785-91.

[87] Matthias A, Kerstin BE, Ohlson BE, Fredriksson JM, Jacobsson A, Nedergaard $\mathrm{J}$, et al. Thermogenic responses in brown fat cells are fully UCP1-dependent. J Biol Chem 2002;33:25073-81.

[88] Kozak LP, Harper ME. Mitochondrial uncoupling proteins in energy expenditure. Annu Rev Nutr 2000;20:339-63.

[89] Harper ME, Himms-Hagen J. Mitochondrial efficiency: lessons learned from transgenic mice. Biochim Biophys Acta 2001;1504: $159-72$.

[90] Gong DW, Monemdjou S, Gavrilova O, Leon LR, Marcus-Samuels CJ, Chou CJ, et al. Lack of obesity and normal response to fasting and thyroid hormone in mice lacking uncoupling protein-3. J Biol Chem 2000;275:16251-7.

[91] Arsenijevic D, Onuma H, Pecqueur C, Raimbault S, Manning BS, Miroux B, et al. Disruption of the uncoupling-2 gene in mice reveals a role in immunity and reactive oxygen species production. Nat Genet 2000;26:435-9.

[92] Williams RS, Wagner PD. Transgenic animals in integrative biology: approaches and interpretations of outcome. J Appl Physiol 2000;88:1119-26.

[93] Liu X, Rossmeisl M, McClaine J, Riachi M, Harper ME, Kozak LP. Paradoxical resistance to diet-induced obesity in UCP1-deficient mice. J Clin Invest 2003;111:399-407.

[94] Nagai N, Sakane N, Ueno LM, Hamada T, Moritani T. The -3826 A$>\mathrm{G}$ variant of the uncoupling protein-1 gene diminishes postprandial thermogenesis after a high fat meal in healthy boys. J Clin Endocrinol Metab 2003;88:5661-7.

[95] Dulloo AG, Jacquet J, Montani JP. Pathways from weight fluctuations to metabolic diseases: focus on maladaptive thermogenesis during catch-up fat. Int J Obes 2002;26(Suppl. 2):S46-57.

[96] Dulloo AG, Jacquet J. An adipose-specific control of thermogenesis in body weight regulation. Int J Obes 2001;25(Suppl. 5):S22-9. 
[97] Dulloo AG, Girardier L. Adaptive changes in energy expenditure during refeeding following low calorie intake: evidence for a specific metabolic component favouring fat storage. Am J Clin Nutr 1990;52:415-20.

[98] Dulloo AG, Seydoux J, Girardier L. Dissociation of enhanced efficiency of fat deposition during weight recovery from sympathetic control of thermogenesis. Am J Physiol 1995;269:R365 - 9.

[99] Dulloo AG, Girardier L. Adaptive role of energy expenditure in modulating body fat and protein deposition during catch-up growth after early undernutrition. Am J Clin Nutr 1993;58:614-21.

[100] Dulloo AG, Girardier L. Influence of diet composition on energy expenditure during recovery of body weight in the rat: implications for catch-up growth and obesity relapse. Metabolism 1992;41: $1336-1342$

[101] Arsenijevic D, Girardier L, Seydoux J, Chang HR, Dulloo AG. Altered regulation of energy balance and cytokine gene expression in a murine model chronic toxoplasmosis. Am J Physiol 1997; 272:E908-17.

[102] Cettour-Rose P, Rohner-Jeanrenaud F, Samec S, Summermatter S, Mainieri D, Montani JP, et al. Redistribution of glucose utilization from skeletal muscle to adipose tissue during suppressed thermogenesis favouring catch-up fat after low food intake. Int J Obes 2004 [in press].

[103] Dulloo AG, Jacquet J. The control of partitioning between protein and fat during human starvation: its internal determinants and biological significance. Br J Nutr 1999;82:339-56.

[104] Henry CJK, Rivers J, Payne RR. Protein and energy metabolism in starvation reconsidered. Eur J Clin Nutr 1998;42:543-9.
[105] Henry CJK. Influence of body composition on protein and energy requirements: some new insights. In: Davies PSW, Cole TJ, editors. Body composition techniques in health and disease. United Kingdom: Cambridge University Press; 1995. p. 85-99.

[106] Dulloo AG, Jacquet J, Girardier L. Autoregulation of body composition during weight recovery in humans: the Minnesota experiment revisited. Int J Obes 1996;20:393-405.

[107] Keys A, Brozek J, Henschel A, Mickelson O, Taylor HL. The biology of human starvation. Minneapolis: University of Minnesota Press; 1950.

[108] Dulloo AG, Jacquet J. Adaptive reduction in basal metabolic rate in response to food deprivation in humans: a role for feedback signals from fat stores. Am J Clin Nutr 1998;68:599-606.

[109] Dulloo AG, Jacquet J, Girardier L. Poststarvation hyperphagia and body fat overshooting in humans: a role for feedback signals from lean and fat tissues. Am J Clin Nutr 1997;65:717-23.

[110] Rothwell NJ, Stock MJ. Regulation of energy balance in two models of reversible obesity in the rat. J Comp Physiol Psychol 1979; 93:1024-34.

[111] Almeida NG, Levitsky DA, Strupp B. Enhanced thermogenesis during recovery from diet-induced weight gain in the rat. Am J Physiol 1996;271:R1380-7.

[112] Griffiths M, Payne PR, Stunkard AJ, Rivers JP, Cox M. Metabolic rate and physical development in children at risk of obesity. Lancet 1990;336:76-8.

[113] Ravussin E, Lillioja S, Knowler WC, Christin L, Freymond D, Abbott WG, et al. Reduced rate of energy expenditure as a risk factor for body-weight gain. N Engl J Med 1988;318:467-72. 